Economía, Sociedad y Territorio, vol. v, núm. 17, 2005, 1-25

\title{
Políticas urbanas para o espaço global
}

\author{
Tamara Tania Cohen EgLer*
}

\begin{abstract}
This paper shows the fact that we are undergoing a transition process created by the new information and communication technologies that transform the spatial processes. Its configuration is the result of having fragmented cities in different places of the world, which are connected by informational fluxes of technological support that get articulated to relate the place with the global fluxes and create a new spatial totality without a scale. We propose to examine how the urban policies in Brazil are getting more associated with the production of localised interventions, in the sense of connecting the ports of our cities with the global space. In order to achieve our task, we start by examining the new forms of the global space, the logics and planning of the urban policies and the effects in the social space to unravel the power to destroy the communities of the place and redefine the social use of space in benefit of the interest of the globalised elites.
\end{abstract}

Keywords: New technologies, global space, urban policies, porto.

\section{Resumo}

O essencial do nosso trabalho é demonstrar como estamos diante de um processo de transição, resultante das novas tecnologias de comunicação e informação, que transforma os processos espaciais. Podemos ler sua configuração na articulação de fragmentos de cidades, em diferentes localizações do mapa do mundo, conectadas por fluxos informacionais de suporte tecnológico que se articulam ligando o local aos fluxos globais e constituindo uma nova totalidade espacial aescalar. A nossa proposta é examinar o modo como as políticas urbanas no Brasil estão cada vez mais associadas à produção de intervenções localizadas, que objetivam conectar fragmentos das nossas cidades ao espaço global. Para avançar nessa tarefa, o nosso ponto de partida é examinar as novas formas do espaço global, a lógica e o desígnio das políticas urbanas e os efeitos sobre o espaço social. No sentido de desvendar o seu poder de destituir as comunidades locais e redefinir o uso social do espaço em benefício das elites globais.

Palavras chaves: novas tecnologias, espaço global, políticas urbanas, porto.

* Instituto de Pesquisa e Planejamento Urbano e Regional, Laboratório Espaço na Sociedade da Informação (IPPUR/UfRJ). Correo-e: tamaraegler@uol.com.br 


\section{Introdução}

As políticas urbanas globais estão na ordem do dia, e a sua importância está expressa na competição entre cidades dos mais diversos países do mundo pelas candidaturas para sediar as Olimpíadas, nos projetos de renovação das zonas portuárias, nas políticas de preservação do Patrimônio Imobiliário.

O essencial do nosso trabalho é demonstrar como estamos diante de um processo de transição que forma um novo espaço que, por sua vez, se transmuda e se sobrepõe às formas anteriores do espaço precedente. Sua nova configuração resulta de fragmentos de cidades, em diferentes localizações do mapa do mundo, conectadas por fluxos informacionais de suporte tecnológico. Isso quer dizer que esse suporte conecta formas espaciais, materiais e fluxos comunicacionais. Sua representação pode ser lida na conexão de espaços locais - fragmentos urbanos - e processos comunicacionais - fluxos digitais - que se articulam e originam um novo espaço que denominamos global, ligando o local com fluxos globais e constituindo uma nova totalidade espacial aescalar.

Para compreender o seu significado, torna-se imprescindível observar o desenvolvimento da formação desse espaço que deriva das tecnologias de comunicação e informação. Esse espaço de tecnologia informática forma uma nova rede de fluxos informacionais que articula fragmentos de espaços locais.

É, portanto, um novo espaço que se sobrepõe ao anterior e que pode ser percebido através de uma metáfora de rede, em que nas suas conexões vamos encontrar fragmentos de espaços locais que formam uma nova totalidade espacial. A sua complexidade pode ser lida pela vinculação dos fluxos do ciberespaço informacional aos fragmentos de cidades que lhe são conectados.

Para tornar visível o invisível, o nosso ponto de partida está inscrito no advento de novas tecnologias de comunicação que possibilitam a formação de novos fluxos tecnológicos. Estes, por sua vez, possuem uma forma com múltiplas faces e possibilitam a criação de um espaço imaterial, fluido, cuja arquitetura constitui uma rede infinita e cujas conexões configuram centros em que se sobrepõem fragmentos urbanos. É a forma espacial da sociedade global.

Essa nova espacialidade produz novas formas de urbanização 'translocal', como alertam Limonad e Randolph (2001). Invisí- 
vel, exige uma pesquisa que reconheça a natureza mesma dos novos processos espaciais que redefinem a vida cotidiana no lugar. Estudar as determinações de políticas urbanas na formação do espaço global é o objetivo principal deste estudo.

Propomos examinar o modo como as políticas urbanas no Brasil estão cada vez mais associadas à produção de intervenções localizadas, no sentido de conectar fragmentos das nossas cidades ao espaço global. Para avançar nessa tarefa, o nosso ponto de partida é examinar as novas formas do espaço global, a lógica e o desígnio das políticas urbanas e os efeitos sobre o espaço social. E demonstrar como os resultados dessas políticas estão ligados aos interesses das elites globalizadas e isolam as comunidades do lugar.

\section{O espaço global}

Podemos perguntar: quais são as formas do espaço global?

Para responder a essa indagação, baseamo-nos inicialmente nas tecnologias de comunicação que possibilitam a formação de um espaço que resulta da conexão entre fragmentos de cidades e redes de técnica informática, permitindo a realização dos fluxos na escala global. Os fragmentos locais são os que se transformam em objeto das políticas, tais como portos, aeroportos, sistema de hotéis, lugares com patrimônio cultural material e imaterial, e as redes são as que possuem uma forma com múltiplas faces que se unem pelos fluxos imateriais de informação e comunicação. Essa articulação entre fragmentos de cidades e redes técnicas resulta no espaço global.

O objetivo é, então, desvendar as conexões que se estabelecem entre o local e o global, que definem novas formas de urbanização 'translocal', unificam escalas e possibilitam novas formas de mobilidade de capitais, mercadorias e atores ao redor do mundo. Trata-se de tornar transparente o que está ilegível, de dar visibilidade a processos espaciais que configuram novas totalidades e que respondem por novos interesses excludentes.

A nova base técnica de natureza informática cria fluxos comunicacionais que articulam as nações, as empresas, as instituições e as pessoas em novas totalidades. Trata-se, portanto, de observar que os fluxos permitem a articulação de localidades que possibilitam a formação de novas totalidades. É por essa razão que observamos as possibilidades diferenciadas de organi- 
zação das atividades na esfera econômica e também redefinições de organização das estruturas de poder político.

$\mathrm{Na}$ literatura vamos encontrar diferentes interpretações desse fenômeno. Nos primeiros estudos sobre o tema, a construção do conceito focalizou o próprio espaço informacional. Nesse contexto, podemos ler os trabalhos de Pierre Levy (1999a, 1999b), Manuel Castells (1999), que expressam uma expectativa positiva, e o de Milton Santos (1994 e 1996), mais crítico. Esses estudos se propõem a examinar a formação do novo espaço que passa a ser denominado ciberespaço, sociedade em rede, espaço informacional e comunicacional, quando o objeto de investigação está focado nos fluxos informacionais que originam as novas formas da comunicação humana atemporais e aterritoriais.

A interpretação de Pierre Levy, de cunho filosófico, é a natureza do espaço informacional. Ao desvendar-lhe a formação, afirma que não se trata de um espaço geográfico, mas de um espaço feito de conhecimentos, saberes e potências que permitem novas formas de constituição do social. Considera que as novas tecnologias possibilitam a construção de um novo mundo e que é impossível encontrar os mapas desse espaço flutuante, que flui, gira e se dissolve na sua liquidez, determinando um espaço do futuro. É um momento infinito sem possibilidade de retorno, um novo espaço definitivo que transforma a ordem das sociedades.

Observando suas determinações sociais, Castells reconhece o novo paradigma tecnológico e informacional. Considera, sobretudo, um processo que inaugura uma nova cultura de liberdade, dada por novas possibilidades de interatividade que possibilitam novas formas da interação social, novas determinações econômicas, políticas e culturais, definindo uma nova sociedade em rede, quando as formas de utilização da tecnologia são determinantes nos processos de transformação da sociedade. Para ele, as novas tecnologias determinam a reestruturação global e inauguram novas formas de sociedade. Trata-se de compreender que a nova sociedade é capitalista e global e que cada nação deverá ocupar um lugar específico, resultante de sua história e de sua cultura, de seu Estado e de suas relações entre o local e o global.

Para compreender essa complexidade espacial, Milton Santos (1994 e 1996) define o espaço como "meio técnico informacional" e considera que esses novos fluxos possibilitados pelas tecnologias de informática alteram a vida nos espaços urbanos. $\mathrm{O}$ autor define esse novo espaço como um sistema mundo em 
que se estabelecem centros em todas as partes que se inter-relacionam. Nessa direção, a análise observa a relação de cada centro com o sistema mundo, em que cada lugar é ao mesmo tempo mundo. Cada lugar tem sua singularidade, mas para encontrar os novos significados dos lugares é preciso levar em conta os seus efeitos sobre o urbano. Para tanto, é preciso mergulhar nos estudos da vida cotidiana. É uma opção metodológica que sobretudo investiga os efeitos do processo de globalização sobre a vida cotidiana no local, sobre o tratamento geográfico do mundo vivido, que deve considerar os objetos, as ações, a técnica e o tempo. A proposta analítica é então examinar os modos de existência particular que resultam de novas experiências sociais de unificação em torno de objetos em comum. É na vida cotidiana que se realiza a ação social, que na dimensão do cotidiano que inclui novas formas de conexão humana resulta numa oposição entre o local e o global. Nessa interpretação crítica, Milton Santos nos convida a examinar a reinvenção de formas de dominação das nações mais ricas sobre as mais pobres e seus efeitos sobre as localidades.

Interessa-nos observar como se produz uma rede de fragmentos de cidades globais que articulam um conjunto poderoso de negócios associados aos interesses da economia e do poder dominante. $\mathrm{O}$ espaço em rede que se sobrepõe ao mundo contém fluxos comunicacionais que articulam um conjunto de fragmentos de cidades, que se 'colam' uns nos outros, na construção de uma nova totalidade. É um novo espaço formado pela articulação de lugares das cidades que participam da rede, como é o caso de Londres, Paris, Nova York, São Paulo, Tóquio (Sassen, 1998) e também de outras que se propõem a participar, como as cidades do Rio de Janeiro, de Salvador, de Belém, etc.

O processo de globalização das políticas urbanas tem um caráter fragmentário, sua intervenção é pontual e instala processos que mudam os lugares para atender aos interesses das elites globais. No projeto de globalização do mundo, vamos observar como os portos, os aeroportos, a infra-estrutura turística, compõem os espaços locais que, articulados, formam uma nova totalidade global. É nessa fronteira que localizamos a nossa pesquisa, no sentido de desenhar os contornos dos lugares que constituem objeto de uma intervenção que está associada aos interesses dos atores que se beneficiam do processo de globalização.

Dessa articulação decorre um conjunto de processos que transformam as localidades por dentro, decerto porque as atividades 
que resultam do processo de globalização exigem um conjunto de equipamentos para lhes dar suporte, como é o caso de aeroportos, portos, infra-estrutura de comunicação, hotéis, indústria do entretenimento e edifícios destinados às atividades globais em si mesmas. Mais do que isso, a competição para participar dessa rede resulta em políticas urbanas que alteram a estratégia dos investimentos, quando reduz o desenvolvimento urbano à competição entre as cidades e à valorização de espaços urbanos para o circuito globalizado. Vejamos como isso acontece.

\section{Políticas urbanas globais}

Para desvendar a natureza das políticas urbanas no mundo em processo de globalização, o que realmente importa é compreender que o espaço contém formas simbólicas, construídas e sociais. Esse ponto de partida metodológico orienta nossa análise para a percepção de que a categoria espaço deve ser decupada em suas múltiplas determinações que orientam o pensamento, a construção e a ação social no espaço. Concebe o espaço como resultado de um processo que resulta de uma forma de pensar que propõe uma forma de construção de sua materialidade e que abriga o mundo social. Essa análise é importante porque mostra as múltiplas determinações dos processos espaciais, que contêm em si mesmos formas físicas que abrigam relações sociais. Além das formas físicas e sociais, precisamos entender que o espaço deve ser analisado também em suas formas simbólicas, que resultam dos signos que o representam.

A proposta é responder à indagação que examina: quais são as formas de pensar, construir e viver os espaços das políticas urbanas globais? E o essencial do estudo é demonstrar como as políticas urbanas globais realizam uma ação que valoriza a dimensão simbólica do processo espacial e reduz a importância da realidade que faz o espaço social.

No mundo globalizado, as políticas de Estado valorizam a produção do espaço simbólico decorrente da produção de um espaço construído que responde por uma linguagem que distingue os indivíduos pertencentes ao mundo globalizado, sendo que as pessoas do lugar são invisíveis aos objetivos dessas políticas.

Para avançar nessa reflexão, podemos primeiro observar as formas particulares do espaço no mundo globalizado, para depois prosseguir no sentido de reconhecer como as políticas urbanas propõem uma intervenção associada à produção de um 
espaço que se representa por meio de um conjunto de signos que respondem pelo que distingue as elites globais e pelo que ignora as intervenções em benefício de uma vida digna no lugar.

\subsection{Espaço simbólico, construído e social}

Para entender a lógica dos processos espaciais na atualidade global, propomos o desvendamento dos conceitos que iluminam o que é espaço, para então encontrarmos as razões que determinam as políticas urbanas na atualidade.

Para decupar esse objeto e torná-lo compreensível é importante que se examinem as múltiplas determinações dos diferentes espaços simbólico, construído e social, e o modo como eles se constituem em objeto das políticas urbanas globais. Para realizar esse trabalho de decomposição, trabalharemos no sentido de reconhecer quais são os conceitos e as categorias analíticas que constituem as múltiplas determinações do processo espacial.

O espaço deve ser compreendido como uma categoria analítica de natureza totalizadora e de múltiplas determinações (Randolph \& Egler, 2001). Na conceituação mais simples, que podemos encontrar em dicionários, refere-se à distância entre dois pontos e também ao que existe entre duas superfícies. Podemos acrescentar que o espaço é uma categoria abstrata, que se refere a processos de natureza comunicacional, como o espaço simbólico; visível, como espaço construído; relacional, como o espaço social (Egler, 2003). Trata-se de superar a simples interpretação de suas formas aparentes e concretas para penetrar em suas formas invisíveis e sociais.

O espaço construído pode ser observado em suas formas aparentes e materiais, como é o caso dos espaços arquitetônicos, resultantes de um processo de produção específico, historicamente determinado pela técnica construtiva e por formas próprias de organização do trabalho. É produto concreto de uma produção econômica e responde pelas necessidades e funções que lhe são inerentes. Está escrito na arquitetura dos objetos edificados que compõem o processo de urbanização, assim podemos identificar suas diferentes escalas local, regional, nacional e global.

O espaço social é de natureza relacional, define-se pelos fios invisíveis de natureza comunicativa que fazem as relações sociais (Arendt, 1981). No entendimento de Bourdieu (1998), podese representar o mundo social em forma de um espaço, construí- 
do na base de princípios de diferenciações ou de distribuição, constituídos pelo conjunto das propriedades que atuam no universo social considerado, quer dizer, apropriadas para conferir força ou poder nesse universo. Os agentes e grupos de agentes são definidos por suas posições relativas nesse espaço.

Esse poder pode ser definido como o lugar onde se permite que indivíduos se associem tendo em vista a realização de um objeto em comum. Tal objeto comum permite posições e práticas sociais que fundamentam a formação dos grupos, podem ser de natureza econômica, política, cultural ou social e se referem aos vínculos que os homens podem tecer entre si, por meio do poder de unificar para atingir o mesmo objetivo e desenvolver a ação em comum (Bourdieu, 1998).

Esse lugar comum pode ser uma fábrica, uma instituição, um bairro. Constitui os sentidos identitários que constroem as relações sociais, as quais muitas vezes se sobrepõem ao espaço construído, mas têm essência própria. Contém símbolos que hierarquizam os indivíduos no espaço social, acolhe os que são iguais e afasta os diferentes (Bourdieu, 1998). Localiza os grupos sociais no espaço e dita os processos de acolhimento e desenraizamento (Arendt, 1981) tanto os que pertencem quanto os que não pertencem ao espaço social desenhado.

O que existe é um espaço de relações que é tão real como o espaço construído. Os fios invisíveis de natureza comunicativa contêm símbolos que criam as localizações dos agentes nos espaços e que determinam as formas de sua apropriação. O espaço simbólico cumpre funções de inclusão e exclusão e determina os grupos que pertencem e os que não pertencem às determinações ditadas por esses símbolos.

As políticas urbanas têm o poder de produzir discursos que fazem a transformação do espaço e da sua percepção. Os discursos são feitos de posições que dão um sentido comum às práticas sociais. Isso é muito importante porque a percepção do mundo social é diferente para os agentes que interpretam diferentes papéis no seu conjunto.

As políticas urbanas globais desenham um processo de intervenção que propõe a construção de um espaço simbólico que cumpre funções e práticas de prestígio das elites globais, para quem é determinado o uso do espaço. De fato, o espaço urbano local é transformado em espaço urbano global. As propostas de arquitetura produzem um espaço construído, formado por uma linguagem que constitui um conjunto de signos para distinguir os 
que são acolhidos pelo espaço social. Propõem um espaço social hierárquico que acolhe e distingue os grupos globais que participam dos fluxos de turismo internacional e isola os moradores locais, que fazem a sua vida no lugar. Constroem, pois, espaços de diferenças sociais, onde cada grupo fica hierarquicamente localizado em diferentes posições do espaço.

\section{A renovação das zonas portuárias}

Para elucidar o sentido das políticas urbanas globais, esforçamonos para analisar e observar como os princípios da globalização podem ser lidos nas políticas urbanas locais. Consideramos que a política urbana é um processo de intervenção do Estado cujo objetivo é produzir um processo de transformação dos espaços construídos. A nossa leitura centraliza-se nos processos de renovação das zonas portuárias, porque eles são a porta de entrada do capital global.

Podemos começar nossa análise tentando perceber de que modo o espaço construído tem como ponto de partida o projeto de arquitetura e urbanismo que concretiza os objetivos propostos pelos formuladores das políticas. O fato é que o projeto de transformação se inicia por uma interpretação do processo de transformação social realizada pelo conjunto de técnicos e arquitetos que participam dos planos, programas e projetos. É por essa razão que estamos sempre a ler os sonhos dos arquitetos descolados da realidade objetiva e associados ao seu próprio imaginário, afastados dos sonhos de transformação imaginados por aqueles que vivenciam suas próprias realidades. É sempre a mesma história de dominação, interpretar seu mundo no sentido de transformá-lo, tendo em vista uma forma de ver e viver no mundo subordinada à vida e à obra dos seus criadores (Teixeira, 2003).

O exercício da política urbana é de natureza discursiva, quando podemos ler nos espaços propostos a possibilidade de determinar e de dar sentido à linguagem que escreve o espaço simbólico e os grupos sociais que por ele são beneficiados. É o poder da ação política. Possibilita a compreensão de indicar os grupos sociais e as pessoas que se beneficiam da política.

Uma realidade é a da existência humana, a outra é a que é feita de signos que representam a criatividade de um grupo de técnicos e gestores que reservam para si o exercício da criatividade e da produção do bem comum. Monopolizam o processo 
de transformação, no sentido de excluir os que participam da vida no lugar, em nome do seu próprio bem.

São signos que representam um ideário do bem-estar, sem contudo responder pelo processo de transformação que possa realizar esse bem (Lefebvre, 1984). Nos espaços das políticas urbanas globais, esse processo torna-se mais perverso se consideramos que os seus criadores respondem por um imaginário que representa não a vida do lugar, mas os sonhos monumentalistas dos próprios autores, associados a um processo de distinção, dos próprios criadores e dos homens e mulheres que participam do mundo globalizado.

Podemos ler esse desígnio com nitidez na política de revitalização das zonas portuárias em diferentes cidades do mundo. De São Francisco a Buenos Aires, a política de renovação dos sistemas portuários obedece a uma mesma lógica que está vinculada à produção de uma espacialidade suntuosa, própria à simbologia que sustenta a viagem dos poderosos rumo à conquista das cidades mundiais.

Os projetistas desses espaços sonham com um mundo fashion, glamorizado, adequado a uma forma de ver e sentir o mundo que responde pela implacável caneta do seu criador que sonhou com uma espacialidade revitalizada, feita de vidro e alumínio sobre os edifícios que lhe deram origem. Os projetos de renovação e revitalização dos portos de São Francisco, Buenos Aires ou Belém têm a mesma concepção. Estão ligados a uma forma de pensar que valoriza a preservação e a reutilização do patrimônio imobiliário preexistente, com uso socialmente improdutivo. É com base nessa espacialidade que o processo de renovação se dirige a uma produtividade espacial econômica, associada à industria do entretenimento global. Fica tudo com a mesma cara, o mesmo cheiro e o mesmo gosto.

A proposta espacial é muito clara, os edifícios que compunham o antigo Porto Madero foram revitalizados para abrigar atividades habitacionais, empresariais, e de entretenimento, próprias às necessidades dos processos de globalização. Ao percorrermos o porto de Buenos Aires, podemos ler a olho nu os interesses dos projetos de renovação. O projeto vincula-se à criação de espaços destinados às empresas globais e aos turistas da era global.

O processo de revitalização do Porto Madero custou à população argentina milhões de dólares e dez anos de trabalho. Vejamos como isso ocorreu: os empréstimos internacionais visavam 
também investir nessa área, em benefício da inserção de Buenos Aires na rede de cidades globais. É uma lógica perversa, porque abre uma porta para empréstimos internacionais que são revertidos, no plano local, para atender às próprias necessidades de quem emprestou. Uma estratégia de dominação associada a um discurso de emancipação. Impõe ao outro sua própria interpretação de desenvolvimento, no sentido de transformá-la em beneficio de si mesmo.

São conhecidos programas de revitalização dos portos, assim como seus efeitos. Por ocasião da revitalização de Porto Madero, no auge da inserção da Argentina no sistema global, quando os contratos e parcerias estavam sendo assinados e as dívidas constituídas, o porto era renovado, com projeto de arquitetura assinado por grandes nomes, a partir de um discurso de novas parcerias entre Estado e capital. Durante o período em que a Argentina se imaginava num ciclo de muita riqueza e o dinheiro era torrado em projetos desnecessários, o Porto Madero viveu um período de efervescência global, com o turismo incrementado pelas atividades próprias ao processo para o qual havia sido construído. Instalaram-se as empresas, os hotéis e os restaurantes necessários ao desenvolvimento do processo econômico globalizado.

Com a crise da Argentina, sua imagem principal pode ser lida no mesmo Porto Madero, com o encerramento de muitas atividades nele localizadas. As empresas foram fechadas e os restaurantes encerraram suas atividades. Os muitos metros quadrados de área construída tiveram suas atividades minimizadas. Agora, em 2004, observa-se uma revitalização com a desvalorização da moeda que ampliou os fluxos turísticos internacionais.

A revitalização do porto de Belém (Arruda, 2003) expressa a mesma lógica. Foram revitalizados grandes galpões para a instalação de atividades de entretenimento associadas ao turismo. $\mathrm{Na}$ arquitetura moderna, podemos perceber uma intenção de desenho que realiza a mais rigorosa das espacialidades modernas, que se propôs a construir um espaço homogêneo e tecnicamente racional que produz uma espacialidade rigorosamente clean, branca e amorfa da vida do lugar. No percurso desse espaço, reconhecemos a homogeneidade da modernidade, que chegou a detalhar a mesa e a cadeira para todos os restaurantes do lugar. E o resultado é um espaço frio, destituído de invenção e sem colorido. No meio da Amazônia, tem-se a sensação de estar em Amsterdã. 
O resultado no sentido da apropriação social é conhecido: as atividades econômicas previstas não suportam os altos custos das instalações e o encerramento de lojas e restaurantes faz parte do dia-a-dia do lugar. Trata-se, portanto, de um processo que valoriza o uso social exclusivo para o fluxo de turistas e tem por resultado um processo de dilapidação econômica e exclusão social.

As atividades da globalização são efêmeras e têm temporalidade definida. Sabemos também que o capital global não investe localmente para não ter seus capitais atados a atividades de longa duração. Os processos de produção duram o tempo da acumulação; quando esta se esgota, os capitais migram para novos espaços. A efemeridade atinge os espaços construídos, e o comando é realizado pela política global, que migra em busca de conexão na rede de novas espacialidades. Isso é muito grave porque expressa a transitoriedade dos processos no âmbito local.

Como exemplo desse mecanismo, podemos citar Buenos Aires, uma das primeiras cidades da América Latina a renovar seu porto, no momento em que a Argentina estava em processo de conexão ao sistema internacional. A cidade do Rio de Janeiro se candidata à rede de cidades globais, formulando então, entre outras, uma política de renovação e revitalização de sua zona portuária. As datas não mentem: no ano de 2000, inicia-se a crise da Argentina e, junto com ela, os projetos de renovação do porto do Rio de Janeiro.

Essa é a política que produz o projeto de revitalização da zona portuária da cidade do Rio de Janeiro. Tem gente sonhando com um grande projeto que resulte numa ampliação das atividades de turismo na cidade. A equação é a mesma: incrementar a construção de um projeto de arquitetura que renove o uso do patrimônio imobiliário para empresas, atividades de entretenimento e habitação para alto poder aquisitivo. Ou melhor, renovar o patrimônio imobiliário para criar um novo uso social, focado nas atividades necessárias ao processo de globalização.

Toma-se um espaço depauperado pela sucessão de erros do passado, para inventar uma nova vida, resultante de uma ação que combina o Estado e o capital local aos interesses do sistema global, sem sociedade local. O projeto de transformação do espaço local em espaço global ignora o espaço social. A leitura dos projetos de arquitetura revela a ausência da comunidade local, o total menosprezo pela reprodução da vida cotidiana, no ininterrupto processo de reconstituição das relações anteriores. A re- 
novação dos lugares aniquila a história das pessoas que dão origem ao lugar.

Nada mais oportuno do que lembrar o projeto de Jean Nouvell para o programa de revitalização da zona portuária do Rio de Janeiro. A proposta de arquitetura era um edifício que, em um mergulho nas águas da Baía da Guanabara, procurava a construção de um espaço edificado extraordinário dentro dos princípios da pós-modernidade, para dignificar e produzir o reconhecimento do autor, em posição estratégica do campo da arquitetura (Bourdieu, 1998).

Estavam previstos para a realização, apenas do projeto do Museu, uma soma de 18 milhões de dólares. Tal dimensão fica ainda mais palpável em comparação aos 400 milhões de dólares que deverão ser aplicados no transcorrer do próximo ano no programa Fome Zero, do governo Lula. Foi necessário um amplo movimento social para impedir as negociações do governo César Maia com os diretores do Museu Guggenheim. Afinal, depois de muitas negociações, o movimento popular ganhou a liminar que questionava a legalidade do processo orquestrado pela prefeitura. O fato é que os diretores do Museu desistiram da construção da sua filial no Rio de Janeiro.

As políticas de construção do espaço enfocam uma ação associada à renovação e à revitalização do patrimônio imobiliário, elas são associadas aos objetos que compóem os espaços, às coisas que fazem a materialidade. A política urbana quer produzir um novo espaço construído que seja capaz, por si, de construir e formar um novo homem. O discurso manifesto está construído segundo o modo como o Estado produz o espaço construído, quando são criadas as condições para a reprodução do bem-estar coletivo. Essa construção mental garante o primado do Estado sobre a política urbana como cenário do processo econômico que produz e reproduz as possibilidades de ação social (Lefebvre, 1991).

Mas, como nos alerta Lefebvre, o espaço reconstruído não conduz necessariamente à formação de um novo homem, dentro de uma sociedade mais justa. Para tanto, é preciso olhar para o espaço social, que é feito de pobreza, dignidade, integração, pertencimento, trabalho, subsistência e embelezamento. $\mathrm{O}$ espaço construído é ponto de partida para a construção do espaço social. É preciso inverter essa relação e começar pelo espaço simbólico e suas determinações na formação do espaço social. 


\section{Espaço simbólico nas políticas globais}

O espaço simbólico está escrito no mundo das representações em objetos que plasmam uma função de distinção realizada por meio de um conjunto de signos que fazem seu discurso manifesto e que têm por função distinguir quem o possui (Baudrillard, 1995). Esse conceito ajuda a entender como o poder do símbolo está associado a objetos que têm um valor de uso, sendo que o valor simbólico responde por uma significação no discurso social inconsciente. Essa compreensão abre uma perspectiva analítica que permite ver e ler as formas do espaço construído, para além de suas funções meramente ligadas ao seu uso.

Os espaços construídos resultam em um conjunto de objetos que contêm em si próprios uma representação simbólica, que extrapola seu valor de troca e de uso. Poderíamos fazer uma analogia para compreender que o espaço provém de processos de construção, localizados no mundo econômico, que expressam representações simbólicas que se associam à cultura e que são cenário de formas específicas de práticas sociais presentes no universo relacional do espaço social.

Se focarmos nossa atenção nas propostas de arquitetura dos projetos de revitalização dos portos de Belém ou do Rio de Janeiro, podemos observar que eles revelam a produção de uma espacialidade amorfa, destituída de sua construção local. É uma espécie de máscara que plasma o ideário simbólico de distinção global. É por essa razão que no porto de Belém, no meio da Amazônia, encontramos um projeto que homogeneíza os espaços e lhes dá um tratamento da suntuosidade moderna, simplesmente ignorando as concepções espaciais do lugar e impondo um desenho urbano alheio às suas especificidades.

Quando a função primordial do espaço simbólico das políticas urbanas globais está vinculada ao sentido de ostentar uma determinada posição social de quem o possui, os espaços assim concebidos por essa simbologia ostentatória estão destituídos de funções sociais. Trata-se sobretudo de realizar uma função social de prestígio. Esse valor simbólico socialmente acordado pode ser reconhecido pelo discurso específico dos espaços construídos, que, através de um sistema de signos, expressam distinção. Quer dizer, expressa um determinado código formal que conduz para uma determinada prática social (Baudrillard, 1995).

O espaço simbólico é invisível, plasmando-se em todos os objetos e pessoas que participam de sua totalidade. É necessário 
descobrir onde ele se deixa ver menos. É percebido com a cumplicidade daqueles que estão sujeitos com aqueles que o exercem (Bourdieu, 1998). Isso quer dizer que resulta tanto das formas de dominação como das de subordinação. Isso quer dizer que o espaço simbólico decorre de um conjunto de códigos que se plasmam nos objetos e nas ações e respondem por um código específico, socialmente reconhecido. Realiza-se mediante a ação dos criadores que o conceberam e dos que o usufruem e que dele se beneficiam. Está em toda parte, o que importa é tornar visível o invisível.

Todo espaço contém em si mesmo um conjunto de símbolos, lhe atribui significados e sentidos e define uma ordem de produção e apropriação do espaço.

Esse processo propõe uma ordem na posição dos grupos sociais no espaço, que restringem seu uso aos grupos sociais hegemônicos do processo de globalização. Os símbolos desse conjunto são percebidos pelos grupos que participam do mundo global, formam um consenso, marcam as práticas de apropriação social no espaço e da ordem de sua reprodução.

O espaço simbólico tem funções políticas e constitui um instrumento de dominação. Representa a cultura das elites e, através da comunicação entre os seus membros, realiza o poder de integração social dos grupos sociais globalizados. Produz o acolhimento de pessoas que participam dessa classe e distingue-a de outras classes assegurando a sua exclusão, legitimando distinções, definindo uma cultura dominante global.

O espaço é produto desse conjunto de símbolos que suscitam uma forma de pensar e de propor sua produção e que definem a sua forma de apropriação. Podemos ler essa dimensão em todas as espacialidades que compõem os projetos urbanos globais, desde os de preservação do patrimônio histórico até os de construção de aeroportos e hotéis.

A produção simbólica do espaço tem por objetivo impor princípios de dominação, realizada pela ação dos seus produtores, que detêm o poder de determinar os símbolos de distinção constituintes dessas espacialidades e convenientes às classes dominantes globais, que desviam em seu proveito o poder de definilos, situando-os no topo dos valores da hierarquia espacial. Isso no sentido de subordinar os que não participam desses valores e de barrar-lhes a possibilidade de conviver nesse espaço (Bourdieu, 1998). 
A produção da espacialidade global resulta de determinação política associada ao "direito de definir e impor o significado do espaço comum” (Bauman, 1999, p. 8). Esse é o fundamento da contemporaneidade, em que as políticas urbanas globais constituem um instrumento de dominação pelos direitos de dar sentido comum ao mundo. $\mathrm{Na}$ atualidade, a propriedade do espaço já não representa um fundamento para o exercício do poder; o que determina as formas de poder é a possibilidade de dar sentido comum à compreensão do mundo. Certamente os processos de dominação simbólica são de natureza política, porque perpetuam as relações de dominação, agora exercidas pelas elites globais na esfera cultural. É uma produção lingüística da realidade, é uma linguagem que autovalida a política e legitima o direito de impor modelos de vida e o poder dessas elites (Hardt e Negri, 2000).

\section{Política urbana global e espaço social}

A cultura não é uma simples efervescência (Cantanhede, 2003), mas é ativa e específica, ligada a um modo de vida. Isso quer dizer que a cultura não é apenas a manifestação do que se convencionou chamar de cultura de elite, ou, segundo o senso comum, de o conjunto de pessoas cultas com admirável acervo cultural. Não, a cultura é muito mais que isso, diz respeito à alma, ao espírito, à inteligência de uma nação. E opera no tecido social, porque os fios invisíveis de natureza comunicativa que produzem a integração social têm sua origem na essência cultural dos coletivos sociais.

Qual é a ordem cultural que encontramos nos projetos de políticas urbanas associadas ao espaço globalizado?

No projeto de revitalização da zona portuária, a questão da cultura vincula-se à produção de uma espacialidade simbólica inserida no espaço global, capaz de atrair a vontade de conhecer e de estar de milhares de turistas que dispõem da mobilidade de estar em qualquer lugar do mundo, a qualquer hora, pelo simples prazer de apreciar a monumentalidade de um projeto de arquitetura global.

É como um trator que passa por cima das formas de pensar, de ser e de estar no mundo, que fazem parte da memória social da localidade. A cultura de uma nação não é necessariamente homogênea, o Brasil é um país multicultural, onde encontramos diferentes culturas regionais. O que interessa é que para cada espaço vamos reconhecer especificidades culturais próprias ao 
lugar. A cultura, então, como nos alerta Lefebvre, é ativa, específica, ligada a um modo de vida, sendo decisiva nas formas de operar essa existência social particular.

Ela possibilita a 'cola' que mantém os homens em um lugar comum. Quando observamos um rompimento da vida cotidiana, podemos afirmar que ele ocorreu exatamente porque as pessoas não responderam mais por essas especificidades ativas da cultura, ou seja, porque se perderam os elos que fazem o tecido do espaço social.Enquanto a cultura estiver ativa, as antigas relações reconstituem o cotidiano e a vida se reproduz.

O que as políticas urbanas globais fazem com a vida cotidiana no local?

Nos projetos de revitalização das zonas portuárias, seja a de Buenos Aires, a de São Francisco, a de Belém ou a do Rio de Janeiro, vamos reconhecer a produção de uma espacialidade que ignora as especificidades da cultura que opera o social local, para valorizar uma outra cultura que representa o imaginário de elites que participam dos fluxos globais.

Isso é muito importante para entender a lógica simbólica da política urbana global, que produz uma espacialidade para fortificar os interesses das classes que dominam o sistema globalizado. É por essa razão que podemos ler um conjunto de símbolos que conformam as espacialidades, que definem a cultura de quem irá usufruir e excluem a cultura das pessoas que fazem a vida do lugar.

Trata-se de um grande problema, porque essas políticas urbanas respondem ao modelo formulado por interesses externos que propõe um projeto que é exterior ao mundo local e sobrepõe à cultura que existe um novo conjunto de códigos que destrói os códigos que a antecederam e impõe a construção de uma nova espacialidade. É um poder de dominação que transforma os usos espaciais em benefício das instituições que os promoveram e das classes dominantes que deles usufruem, estranhos aos interesses das pessoas que fazem a vida dos lugares.

O poder é agora exercido mediante formas de pensar que organizam o cérebro em sistemas de comunicação, de redes de informação, e os corpos em sistemas de bem-estar, em atividades monitoradas, com o objetivo de criar nas pessoas que participam desse turismo internacional um estado de atenção, destituído do sentido da vida e da criatividade. É a construção de uma forma de pensar que aliena o sujeito de sua própria condição humana, 
para ser transformado num objeto stricto sensu da política (Hardt e Negri, 2000).

Essas determinações podem ser lidas em diferentes manifestações da política urbana global. Por exemplo, a política de revitalização do porto da cidade do Rio de Janeiro centraliza seus objetivos principais na produção de um ícone, como foi o caso do Museu Guggenheim, que representa um conjunto de símbolos que respondem pelos interesses de uma cultura dominante que não tem nada a ver com a cultura local. Assim, o museu é reconhecido como um meio capaz de catalisar o desenvolvimento da política de revitalização do porto da cidade do Rio de Janeiro.

Essa forma de dominação age através da subjetividade que se realiza mediante o conhecimento, a comunicação e a linguagem. Devemos entender suas determinações por meio da compreensão dos processos intelectuais e corpóreos, quando o objeto da dominação está associado aos corpos e ao afeto, que são fundamentais nesse contexto analítico. Trata-se, portanto, de levar ao bem-estar do corpo e da subjetividade através da manipulação dos afetos. A necessidade ininterrupta de preenchimento da alma por meio de estímulos é capturada pela lógica dessa política urbana, subordinando a criatividade dos homens aos desígnios da cultura global. Os sujeitos dessa política são os próprios turistas e elites que se movem pelo mundo em busca de uma emoção perdida, em busca de uma relação afetiva. O cerne da política é, por um lado, emocionar e, por outro, excluir, já que é capaz de dominar utilizando poderosos instrumentos de manipulação cultural.

As políticas urbanas globais vendem as cidades como mercadorias capazes de criar estímulos à subjetividade. Estão associadas à produção de estímulos que produzem novas necessidades, relações sociais, corpos e mentes. Nessas estratégias políticas, observamos uma inversão em que a "vida é levada a trabalhar a produção e a produção é levada a trabalhar a vida" (Hardt e Negri, 2000).

É através dos sistemas de comunicação que se expressa e organiza a rede de cidades mundiais, e é através das conexões de redes técnicas que se produzem as condições de mobilidade. E que se controla o sentido do imaginário que percorre as redes. Constrói-se um imaginário que fica canalizado nos fluxos da comunicação global, em que se representam as práticas que conduzem ao bem-estar do corpo e da mente. Assim, a mobilidade pas- 
sa a ser uma condição de bem-estar. Estar em aeroportos, hotéis e museus é pertencer aos espaços sociais das práticas que moldam o bem-estar no mundo (Hardt e Negri, 2000), num movimento ininterrupto de distinção.

Os resultados dessas políticas são muito graves, porque em nome de uma ação discursiva de construção e renovação dessa espacialidade encontramos um processo que ignora o código cultural da localidade e impóe um novo código que faz a defesa de formas espaciais plasmadas de uma simbologia exterior à cultura local. Ele vem para impor um modelo de utilização do espaço pelas elites globais, a quem efetivamente se destinam as políticas urbanas no mundo atual.

O discurso manifesto é assim: a atração de capitais internacionais produz uma espacialidade própria às atividades culturais consideradas de topo na ordem internacional, que exercem fascínio sobre as multidões de turistas que andam pelo mundo. Esses investimentos têm o poder de catalisar um outro conjunto de capitais globais na construção de uma infra-estrutura hoteleira e em outras atividades necessárias à atração desse contingente de turistas, o que resulta na entrada de recursos em moeda fortificada que constituem preciosidades para o desenvolvimento das atividades turísticas da nossa cidade. Aos habitantes da localidade restam os microfinanciamentos que irão possibilitar a abertura de pequenos negócios na franja do espaço revitalizado.

A estratégia da ação é investir na construção dessa espacialidade para atrair os fluxos de turistas que inundam os espaços do lugar, possibilitando a entrada de moeda internacional. Assim fortificada, a economia local passaria ao desenvolvimento econômico e à justiça social.

Conhecemos bem os limites dessas teses. A novidade é que se levantam empréstimos internacionais, que se acumulam na nossa dívida. No entanto, são recursos orientados para a construção de espaço que responde com um conjunto de signos que representam interesses alheios ao lugar. Nessa estratégia pelo poder de dominação, é produzida uma espacialidade para abrigar práticas sociais que excluem as comunidades locais dos códigos de sua existência cotidiana. Produz uma separação extrema entre a minoria que se move nos espaços globais e a maioria que vive em extrema pobreza nas comunidades.

Essas são as novas estratégias de dominação, agora não mais associadas ao exercício do poder sobre o espaço construído, mas 
sobre o espaço simbólico e o poder de fazer "ver e crer". Representam a invenção de novas estratégias de dominação, agora de elites que exercem o poder sobre a existência cultural.

\section{Espaço social e resistência aos projetos globais}

O poder local irá impor limites aos desígnios das elites globais. O fato é que iremos encontrar frentes de resistência social que se expressam por meio das organizações sociais de base, como associações de moradores que se opuseram aos objetivos expressos nos planos de revitalização do porto do Rio de Janeiro e também à política de Estado orquestrada em Belém. Vamos ver como se constrói essa resistência.

A sociedade não é amorfa. No Rio de Janeiro, vamos observar o exercício da resistência social que foi realizada pelas organizações políticas locais, que resultou na desistência dos diretores do Museu Guggenheim de construírem uma filial nessa cidade. Os novos movimentos sociais estão ligados à idéia de que é preciso combater os processos de globalização, procurando delimitar novos objetivos que combatam os próprios objetivos da globalização, dentro do seu próprio campo, para estabelecer forças que reúnam uma organização política alternativa destinada a enfrentar os fluxos e intercâmbios globais (Hardt e Negri 2000).

$\mathrm{O}$ espaço social é o que se percebe entre os indivíduos que participam de uma coletividade. É de natureza imaterial, referese aos vínculos que marcam as relações entre os indivíduos e a sociedade e que formam o tecido social (Arendt, 1981). Representam-se através de fios invisíveis, são de natureza comunicativa, originam-se na cultura e realizam-se no domínio da vida, que transmite os valores e os conhecimentos e que integra os grupos (Habermas, 1988) e reúne os homens em um lugar comum.

A cultura é feita de formas de pensar da totalidade dos indivíduos que fazem parte de uma sociedade; é ela que faz os fios invisíveis que compõem as relações no espaço social. Antecede a produção da ação social e cria social às formas de vida na sua realidade, que se realizam no mundo da vida e podem ser lidas no cotidiano, que se compõem de gestos, de movimentos e de objetos de atividade criadora, em que se criam as condições para que as atividades se auto-reproduzam, em que começa e recomeça a vida, a qual se transforma por modificações lentas e graduais. Estamos falando da teoria do vir a ser, daquilo que será 
possível dentro do mundo que se transforma gradativamente pela ação ininterrupta dos homens (Lefebvre, 1991).

A cultura de uma nação cria o 'mundo da vida'. Quer dizer, o mundo real, aquele que é vivido pelas pessoas e difere do mundo ideal, aquele que é imaginado pelas pessoas, que está escrito no cotidiano que compõe os acontecimentos na vida dos homens, lidos no conjunto de atividades, produtos e obras que resultam da ação social. O desafio é descobrir as formas espaciais da realidade nela mesma, se está associada às energias práticas, aquelas de que todos os indivíduos dispõem como ser social e que são empregadas para mudar o mundo da vida (Lefebvre, 1991).

É a sociedade que faz a história dos lugares e ela se define pela atividade produtora e criadora dos homens que a compõem. Um projeto de revitalização deve estar ancorado nessa forma de pensar que valoriza as atividades econômicas e culturais, que fazem a vida dos homens no lugar. É preciso focalizar a criatividade e a invenção para alcançar processos de transformação. Olhar para dentro do tecido social e descobrir quais são as atividades que fazem a história do lugar e que necessitam e podem ser valorizadas, sustentadas, amparadas e reconhecidas. Olhar para dentro da casa para ver quem pode criar e o que é necessário para avançar no processo de criação, seja para pequenos ou para grandes negócios.

É a criatividade dentro do espaço social que pode transformar esse espaço de deterioração em espaço de vida. A política urbana que tem por objeto de ação a sociedade, tem por desafio revelar as necessidades do espaço social, no que se refere tanto a atividades econômicas de produção quanto a atividades sociais de reprodução.

Mas simplesmente, em vez de procurar o desenvolvimento mediante uma criação que tem origem global, é necessário amparar a ação das pessoas que participam do social na escala do lugar, nas múltiplas ações que se inscrevem nas diferentes esferas econômica, política e cultural. No lugar do Guggenheim, os museus da cidade; no lugar dos hotéis, a habitação social; no lugar das grifes, a produção têxtil local. É necessário focar diretamente o próprio objeto social que se deseja alcançar, como, por exemplo, um projeto para os que vivem e trabalham no circuito portuário e na cidade do Rio de Janeiro, considerando os valores dos trabalhadores e a riqueza de seu cotidiano.

Trata-se de um desafio: transformar a pobreza em riqueza, criar condições para transformar o trabalho criador em riqueza 
socialmente produzida, porque só a atividade criativa produz a riqueza social. Esta não resulta necessariamente de atividades econômicas, mas está escrita nas atividades culturais e políticas. A prosperidade é social quando todos podem estar incluídos nos processos de criação da subsistência corporal e espiritual. A exclusão aniquila a criatividade e forma um coletivo passivo e infeliz (Lefebvre, 1991).

Os projetos de revitalização da zona portuária da cidade do Rio de Janeiro são excludentes da comunidade. Para alcançar o exercício de uma vida cotidiana plena, é preciso incluir o que existe no lugar. A realidade é escrita pelas pessoas, nas suas casas e nas histórias de vida. A mudança proposta pelos planos de dar vida ao lugar só se realiza através de ação social criativa.

Enquanto perdurarem projetos de transformação associados a sonhos faraônicos de dirigentes e criadores que excluem o social de sua observação, deverão perdurar os erros que fazem a história das políticas sociais de nosso país. São idéias utópicas contidas nas políticas e vinculadas a um processo indireto que faz do desenvolvimento de atividades econômicas o mote da mudança na vida das pessoas, e não a um processo de consolidação das formas de vida na sua realidade tangível. São propostos sonhos que não podem, pela sua própria representação, encontrar oportunidades de realização. A crítica é que as políticas têm por objeto de ação uma estratégia que observa o mundo do dinheiro, enquanto o mundo das pessoas de verdade desaparece e não é considerado pelas mesmas (Lefebvre, 1991).

A história da zona portuária revela uma população portuária que deve ser compreendida à luz dos movimentos de resistência social que lhe deram origem. Mais do que isso, revela uma posição na história cultural de nossa cidade ligada ao samba e aos seus principais intérpretes, festejados nas manifestações artísticas que fazem a vida cotidiana no lugar.

Podemos ler a importância dessa história na dissertação de Fernando Mello (2003), quando focaliza as sucessivas transformações de sua espacialidade e faz ver a efervescente vida social que está impressa no lugar, assim como a tristeza dos espaços remanescentes dos sucessivos projetos de intervenção do estado na construção de um espaço institucional.

As políticas urbanas globais estão associadas a uma ação que ignora a riqueza da vida no lugar e nos alerta para que possamos tornar essas políticas visíveis, procurando compreender para quem e para o que elas foram formuladas. Se estão sendo empre- 
gadas para fortalecer as instituições ou para mudar a vida. É muito importante esse alerta, porque remete à ação do planejamento, no sentido de examinar a forma como empregamos os recursos sociais para que retornem à sociedade e não para que reforcem os interesses exteriores ao mundo de verdade.

Existe, pois, um fosso entre o espaço social real e o espaço simbólico. O espaço global desfaz o espaço social da realidade das condições de vida nas localidades. Quando observamos a realidade do mundo social e os projetos imaginários dos criadores dos espaços globais, observamos uma enorme distância entre a realidade e a imaginação. Lefebvre nos adverte que é preciso ir além disso para entrar no mundo social em si mesmo. Este que queremos reconhecer como principal objeto de políticas urbanas locais.

\section{Bibliografia}

Arendt, H. (1981), A condição humana, Forense Universitária, Rio de Janeiro.

(1993), A dignidade da política, Relume Dumará, Rio de Janeiro.

Arruda, E. (2003), A Orla De Belém, Ocupação e Reconfiguração do Espaço, Dissertação (Mestrado), Instituto de Pesquisa e Planejamento Urbano e Regional-IPPUR/UfrJ, Rio de Janeiro.

Baudrillard, J. (1995), Para uma crítica da economia política do signo, Effos, parte I, Rio de Janeiro.

Bauman, Z. (1999), Globalização: as conseqüências humanas, Jorge Zahar Editores, Rio de Janeiro.

Bourdieu, P. (1998), O poder simbólico, Bertrand, Rio de Janeiro.

Cantanhede, A. T. M. de. (2003), Multidão e solidão na orla em Copacabana, Tese (Doutorado), Instituto de Pesquisa e Planejamento Urbano e Regional (IPPUR/UfRJ), Rio de Janeiro.

Castells, M. (1999), A sociedade em rede, Paz e Terra, São Paulo. 
Egler, T. T. C. (2003), "Espaços da coesão social na era informacional", in: J. Gondar e M. A. Barrenechea, Memória e espaço: trilhas do contemporâneo, Sete Letras, Rio de Janeiro.

Habermas, J. (1988), “A nova intransparência: a crise do estado do bem-estar social e o esgotamento das energias utópicas", Novos Estudos Cebrap, n. 18, São Paulo.

Hardt, M. e A. Negri (2000), Império, Record, Rio de Janeiro.

Léfèbvre, H. (1984), A vida cotidiana no mundo moderno, Alianza Editorial, Madrid.

Levy, P. (1999a), A inteligência coletiva, Edições Loyola, São Paulo.

(1999b), Cibercultura, Editora 34, São Paulo.

Limonad, É. e R. Randolph (2001), “Cidade e lugar. Sua representação e apropriação ideológica”, Revista Brasileira de Estudos Urbanos e Regionais, A3, n. 5, Associação Nacional de Pós-Graduação em Planejamento Urbano e Regional, São Paulo, pp. 11-25.

Mello, Fernando Fernandes (2003), Antecedentes e perspectivas da Zona Portuária do Rio de Janeiro, Dissertação (Mestrado), Instituto de Pesquisa e Planejamento Urbano e Regional (IPPUR/UFRJ), Rio de Janeiro.

Randolph, R. e T. Egler (2001), "O espaço da sociedade da informação", Projeto de pesquisa apresentado ao Edital Universal do CNPq.

Santos, M. (1994), Técnica, espaço, tempo: globalização e meio técnico-científico informacional, Hucitec, São Paulo.

(1996), A natureza do Espaço: técnica e tempo, razão e emoção, Hucitec, São Paulo.

Teixeira, M. C. V. (2003), Vivência com-vivência: conjuntos habitacionais em Belo Horizonte, Tese (Doutorado), Insti- 
tuto de Pesquisa e Planejamento Urbano e Regional (IPPUR/ UFRJ), Rio de Janeiro.

Sassen, S. (1998), As cidades na economia mundial, Studio Nobel, São Paulo.

Enviado: 20 de julio de 2004. Aceptado: 12 de diciembre de 2004.

Tamara Egler es arquitecta y doctora en sociología. Actualmente se desempeña como profesora del Instituto de Investigación en Planeación Urbana y Regional de la Universidad Federal de Río de Janeiro (IPPUR/UFRJ), donde coordina el laboratorio Espacio y Sociedad de la Información. Sus principales líneas de investigación son: comunicación y ciudad, red de ciudades globales, redes tecnosociales y acción colectiva. Entre sus más recientes publicaciones destacan: 1) "Exclusão e inclusão na sociedade do conhecimento", Cadernos IPPUR, Universidad Federal de Río de Janeiro, 2001; 2) "Espaço e coesão social", en M. A. Barrenechea y J. Gondar (coords.), Memória e espaço: trilhas do contemporâneo, Rio de Janeiro, Sete Letras, 2003, y 3) "Planejamento e Território. Reflexões sobre a transição da sociedade industrial para sociedade da comunicação", en A. C. Ribeiro (coord.), O rosto urbano da América Latina, Buenos Aires, Clacso, 2003. 